\title{
BIOAVAILABILITY ENHANCEMENT BY FLOATING MICROBALLOONS OF DIPYRIDAMOLE AND CLOPIDOGREL: IN VIVO PHARMACOKINETIC STUDY
}

\author{
SEELAM RAMYA KRISHNA ${ }^{1}$, A. RAMU ${ }^{2}$, S. VIDYADHARA ${ }^{3}$, A. PRAMEELA RANI ${ }^{4}$
}

1,2,3Department of Pharmaceutics, Chebrolu Hanumaiah Institute of Pharmaceutical Sciences, Acharya Nagarjuna University, Guntur 522510, Andhra Pradesh, India, ${ }^{4}$ Department of Pharmaceutical Sciences, Acharya Nagarjuna University, Guntur, Andhra Pradesh, India Email: ramya.krishna.seelam@gmail.com

Received: 05 Jun 2021, Revised and Accepted: 09 Aug 2021

\section{ABSTRACT}

Objective: In vivo pharmacokinetic studies of clopidogrel and dipyridamole floating microballoons to check their bioavailability enhancement.

Methods: The bioanalytical method development was carried by using HPLC with column Poroshell 120 EC-C 18 ; $4.6 x 100$ mm. The in vivo pharmacokinetic studies were performed in Wistar male rats and the obtained data from the pharmacokinetic parameters were analyzed using PK Solver software.

Results: The developed bioanalytical method was found to be linear in the concentration range of 1-100 ng/ml for clopidogrel bisulfate and 0.02$4 \mu \mathrm{g} / \mathrm{ml}$ for dipyridamole with correlation coefficient of 0.9993 and 0.9987 respectively. The study results showed that the method was simple, linear, accurate and precise. The in vivo studies indicated that the AUC was found to be increased by $33.3 \%$ and $154.5 \%$ for clopidogrel and dipyridamole micro balloons, respectively, when compared to their pure drugs.

Conclusion: The bioanalytical methods development and their validation parameters indicated that the methods are accurate, precise and linear in the studied range of concentrations. In vivo test results infer to the effective, sustained release of both the drugs when formulated as micro balloons and increase in the absorption, thereby enhancing the bioavailability of the drugs. The pharmacokinetic studies also confirmed the increase in the mean residence time of the drugs when formulated as floating microballoons.

Keywords: Clopidogrel bisulfate, Dipyridamole, HPLC, Bioavailability enhancement, Pharmacokinetic studies

(C) 2021 The Authors. Published by Innovare Academic Sciences Pvt Ltd. This is an open access article under the CC BY license (https://creativecommons.org/licenses/by/4.0/) DOI: https://dx.doi.org/10.22159/ijap.2021v13i6.42316. Journal homepage: https://innovareacademics.in/journals/index.php/ijap

\section{INTRODUCTION}

The solubility and the bioavailability of a drug affect the therapeutic efficacy of the drug when released from its dosage form. Solubility is one of the major parameters to attain the desired plasma drug concentration. The poor solubility of the drug may result in a limited absorption further leading to the decrease in bioavailability [1]. Dissolution is the ratelimiting step for drug absorption of poorly water-soluble drugs. The need of bioavailability enhancement so as to increase the therapeutic efficacy of the drug has led to investigate the various approaches to enhance the bioavailability. The physical approaches include solubility enhancement by particle size reduction or by delivery of drugs in a suitable carrier, while the chemical approaches include partial chemical modification by the formation of salts, ester prodrugs and ionic complexes with poorly water-soluble drugs. The alteration of the solidstate by several particle size reduction techniques viz. nanosizing by milling, co-grinding, precipitation, nanosuspension technology, supercritical fluid techniques, complexation of drugs with cyclodextrins, inert polymers, and nanomaterials like dendrimers and carbon nanotubes can improve the dissolution rate.

Various physical and physiological factors affect the release of a drug from its delivery system. Altering these factors help to develop well distinguished and reproducible forms of drug delivery systems. The goal in designing a dosage form into a controlled or sustained drug delivery system is to promote the administration of low doses, enhancement of bioavailability by retaining the dosage form at the site of absorption, uniform drug release, reduction in the fluctuations of plasma drug concentration and enhancement of drug efficacy and safety [2]. The controlled release formulations might be designed as single or multiple-unit drug delivery systems. Multiple unit drug delivery systems tend to be more advantageous than single units as they disperse uniformly along the GIT, help the gastric retention of the dosage form, thereby promoting the drug availability at the site of absorption or a longer period of time and also reduce the inter and intra-subject variability thereby improving the bioavailability of the drug.
Clopidogrel is an anti-platelet drug indicated to reduce the risk of myocardial infarction for patients with non-ST elevated acute coronary syndrome (ACS), belonging to class II drugs of BCS classification with water solubility $0.0118 \mathrm{mg} / \mathrm{ml}$. Dipyridamole, a non-nitrate coronary vasodilator that also inhibits platelet aggregation used to prevent thrombosis in patients with valvular or vascular disorders. It belongs to BCS classification class II drugs having low water solubility and high permeation. It has a water solubility of $0.922 \mathrm{mg} / \mathrm{ml}$. In the work carried by Jain HK et al. [3], it was reported that the precision and accuracy of the method met the criteria laid down in guidance for industry, Bioanalytical method validation, USFDA. From the results of this work, it can be concluded that the developed method is simple, accurate, rapid and precise and hence can be used for analysis of clopidogrel bisulfate in the plasma. It was reported by Vanshiv SD et al. [4] that the pharmacokinetic study comparing pure dipyridamole and dipyridamole microspheres indicated the decrease in $\mathrm{C}_{\max }$ and increase in $\mathrm{T}_{\max }$ inferring to the increase in bioavailability. The sustained release of drug from the microballoons was attained and the bioavailability of the dipyridamole microballoons was enhanced by $30 \%$ than the pure drug in this work. N. J. Joseph et al. [5] reported the in vivo studies of pure drug and drug-loaded hollow microspheres of piroxicam. The pharmacokinetic analysis elucidated that the bioavailability of piroxicam loaded microballoons was enhanced by 1.4 times than the pure drug.

Floating microballoons have the advantage of floating immediately without lag time upon administration. Clopidogrel and dipyridamole are having favorable absorption from the stomach owing to their physicochemical properties and hence are suitable for developing into floating microballoons. In the current research work, the in vivo pharmacokinetic studies were carried out for these two anti-platelet drugs, Clopidogrel bisulfate and dipyridamole formulated as floating microballoons. The pre-optimized formulations in both the antiplatelet floating microballoons were taken for conducting the in vivo pharmacokinetic studies. The pharmacokinetic data obtained in the in vivo studies were analyzed using PK Solver software. 


\section{MATERIALS AND METHODS}

\section{Materials}

Clopidogrel and dipyridamole were obtained as gift samples from Hetero Drugs Pvt. Ltd. All other chemicals were of analytical grade and used were purchased from Merck Specialities Pvt. Ltd.

\section{Methods}

\section{Linearity and range}

\section{a) Clopidogrel bisulphate}

Calibration curve in plasma using HPLC was developed in order to estimate Clopidogrel bisulphate in plasma samples during in vivo studies by referring to the method reported by Muhammad. K. Javed et al. [6] with necessary modifications. Stock solutions of Clopidogrel bisulphate and the internal standard Diclofenac sodium were prepared in methanol and diluted with the mobile phase. Various concentrations of clopidogrel in the range of $1-100 \mathrm{ng} / \mathrm{ml}$ were prepared in the mobile phase, Methanol and Phosphoric acid (25 $\mathrm{mmol}$ ) at a ratio of 80:20, so as to contain the internal standard also at a concentration of $100 \mathrm{ng} / \mathrm{ml}$. These samples were spiked with plasma and extraction was done by liquid-liquid extraction method using acetonitrile. $100 \mu \mathrm{l}$ of the filtrate was injected into the column (Poroshell 120 EC-C 18; 4.6x100 mm) which was maintained at $35^{\circ} \mathrm{C}$. The flow rate of the mobile phase was maintained at $1.1 \mathrm{ml} / \mathrm{min}$. The analyte was estimated using UV detector at a wavelength of $220 \mathrm{~nm}$.

\section{b) Dipyridamole}

Calibration curve in plasma using HPLC was developed in order to estimate dipyridamole in plasma samples during in vivo studies by referring to the method reported by Ting Qin et al. [7] with necessary modifications. The mobile phase used was Methanol and Ammonium acetate $(5 \mathrm{mmol})$ at 80:20 ratio. Stock solutions of dipyridamole and the internal standard diazepam were prepared in methanol and diluted with the mobile phase. Various concentrations of dipyridamole in the range of $0.02-4 \mu \mathrm{g} / \mathrm{ml}$ were prepared in the mobile phase so as to contain the internal standard also at a concentration of $4 \mu \mathrm{g} / \mathrm{ml}$. These samples were spiked with plasma and extraction was done by liquid-liquid extraction method using acetonitrile. $100 \mu \mathrm{l}$ of the filtrate was injected into the column (Poroshell 120 EC-C 18; 4.6×100 mm), which was maintained at $35{ }^{\circ} \mathrm{C}$. The flow rate of the mobile phase was maintained at $0.25 \mathrm{ml} / \mathrm{min}$. The analyte was estimated using UV detector at a wavelength of $283 \mathrm{~nm}$.

\section{Accuracy}

The accuracy of an analytical procedure expresses the closeness of agreement between the value which is accepted either as a true conventional value or an accepted reference value and the value found. Accuracy was determined by replicate analysis of samples with a known amount of analyte using three determinations per concentration. The \%RSD is calculated from the mean of the response (peak area) and the standard deviation $[8,9]$.

\section{Precision}

The precision of an analytical procedure expresses the closeness of agreement (degree of scatter) between a series of measurements obtained from multiple sampling of the same homogeneous sample. The precision of an analytical procedure is usually expressed as the variance, standard deviation or coefficient of variation of a series of measurements. The precision was determined by injecting the sample prepared for ten times and the standard deviation was calculated $[8,9]$. The \%RSD was calculated from the standard deviation and the mean of the response.

\section{Limit of detection and limit of quantification}

The term Limit of detection (LOD) refers to the lowest concentration at which the instrument is able to detect but not quantify and the noise to signal ratio for LOD should be 1:3 and Limit o quantification (LOQ) refers to the lowest concentration at which the instrument is able to detect and quantify and its noise to signal ratio should be 1:10. The slope, intercept and correlation coefficient and the residual standard deviation from the linearity curve were calculated and recorded the results for a limit of detection and quantification [10] formula mentioned.

\section{LOD $=3.3$ (Standard deviation of the response)/slope}

LOQ $=10$ (Standard deviation of the response)/slope

\section{Preparation of floating microballoons}

In a mixture of methanol and diethyl ether, the polymer was dissolved and then in that mixture, the drug was dissolved by subjecting it to mixing for $2 \mathrm{~min}$ on a vertex mixture to attain the organic phase $[11,12]$. Span 80 was added to liquid paraffin to attain the oily phase. On the mechanical stirrer, the oil phase was subjected to stirring and set at different rpms. Under constant stirring, the organic phase was added dropwise to the oil phase. Until the organic solvents were evaporated completely, the stirring was continued for about $4-5 \mathrm{~h}$ to yield microballoons. To remove the liquid paraffin traces, the microballoons thus obtained were washed with petroleum ether and dried.

The various formulation compositions varied were the polymer concentration in the total weight of the microballoons, the concentration of methanol in internal phase, the volume of the internal phase, concentration of the surfactant and the speed of rotation in rpm respectively. Upon performing the characterization studies for all the formulated microballoons, the formulation with $75 \% \mathrm{w} / \mathrm{w}$ polymer, $40 \% \mathrm{w} / \mathrm{v}$ methanol, $7.5 \% \mathrm{v} / \mathrm{v}$ volume of internal phase, $0.25 \% \mathrm{w} / \mathrm{v}$ surfactant and 400rpm was taken as the optimized formulation in both clopidogrel microballoons and dipyridamole microballoons.

\section{In vivo pharmacokinetic studies}

Adult Wistar male albino rats $(275 \pm 25 \mathrm{~g})$ were used to perform the oral bioavailability study. The IAEC approval number of the current work is 1529/PO/Re/S/11/CPCSEA/CHIPS/IAEC8/PRO-05/202021 , and the animals for the study were procured from the Mahaveer Enterprises, Hyderabad. Under standard laboratory conditions, the animals were kept on a $12 \mathrm{~h}$ light/dark cycles at $25^{\circ} \mathrm{C}$ temperature and $50 \%$ relative humidity. The animals were homed in polypropylene cages with free access to a standard laboratory diet and water intake was ad libitum. In the rats after fasting overnight (12h) the experiments were performed.

The animals were divided into five groups, with Group 1 being the control placebo group, Group 2 and Group 3 being the reference group administered with Clopidogrel bisulphate and dipyridamole drug suspension, respectively, Group 4 and Group 5 were the test groups administered with the optimized clopidogrel bisulphate microballoons and dipyridamole microballoons respectively. By cautiously placing a stomach tube into the esophagus of witting rats, the selected formulations were given orally by gavage. $1.07 \mathrm{mg} / \mathrm{kg}$ human dose was converted into rate dose by considering the human and rat $\mathrm{Km}$ values [13] and the dose of rate $5.66 \mathrm{mg} / \mathrm{kg}$ was administered to each rat. The sample volumes were adjusted based on the drug present in the formulation and the pure drug suspension. Upon administration, the samples of blood $(300 \mu \mathrm{l})$ were withdrawn from the retro-orbital of rate at different time periods at 0 (pre-dose), 0.5, 2, 4, 6, 8, 12, 18 and $24 \mathrm{~h}$, which were transferred into heparinized containers. The fluid loss due to blood sampling may alter the biopharmaceutics of the drug. In the current work, less than the maximum recommended 3.5 $\mathrm{ml}$ ) was extracted for $24 \mathrm{~h}$ which was about $3000 \mu \mathrm{l}$ of total blood and therefore, the fluid loss might not affect the pharmacokinetic parameters calculated. For the isolation of plasma, the samples were subjected to centrifugation at $800 \mathrm{rpm}$ at $4{ }^{\circ} \mathrm{C}$ for $20 \mathrm{~min}$. The analyte was extracted with acetonitrile after the plasma samples were spiked with an internal standard solution. For the quantification, $100 \mu \mathrm{l}$ of each extract was injected into HPLC.

For the estimation of the pharmacokinetic parameters of clopidogrel and dipyridamole micro balloons, the obtained plasma drug concentration versus time data was subjected to noncompartmental analysis using PK Solver software. The obtained results of $\mathrm{C}_{\max }$, AUC (Area under the curve) and mean residence time (MRT) were statistically analyzed (using data analysis tool in MS Excel) with one-way analysis of variance (ANOVA) to check whether the increase in bioavailability was significant or not. 


\section{RESULTS AND DISCUSSION}
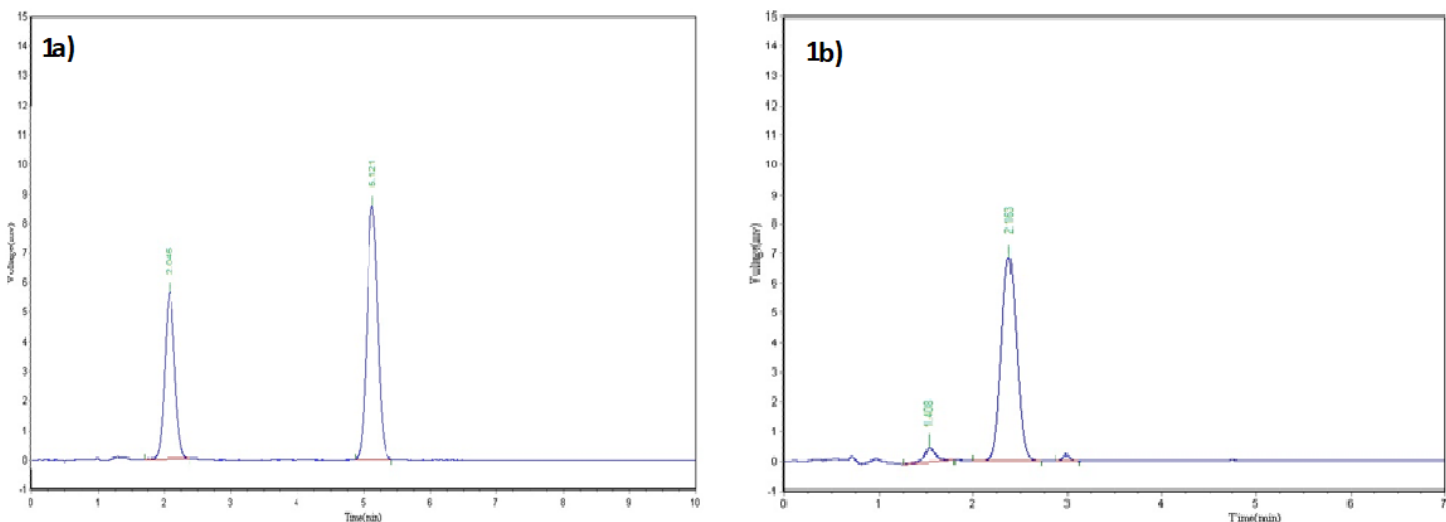

Fig. 1: a) Chromatogram of clopidogrel in rat plasma using HPLC b) Chromatogram of dipyridamole in rat plasma using HPLC
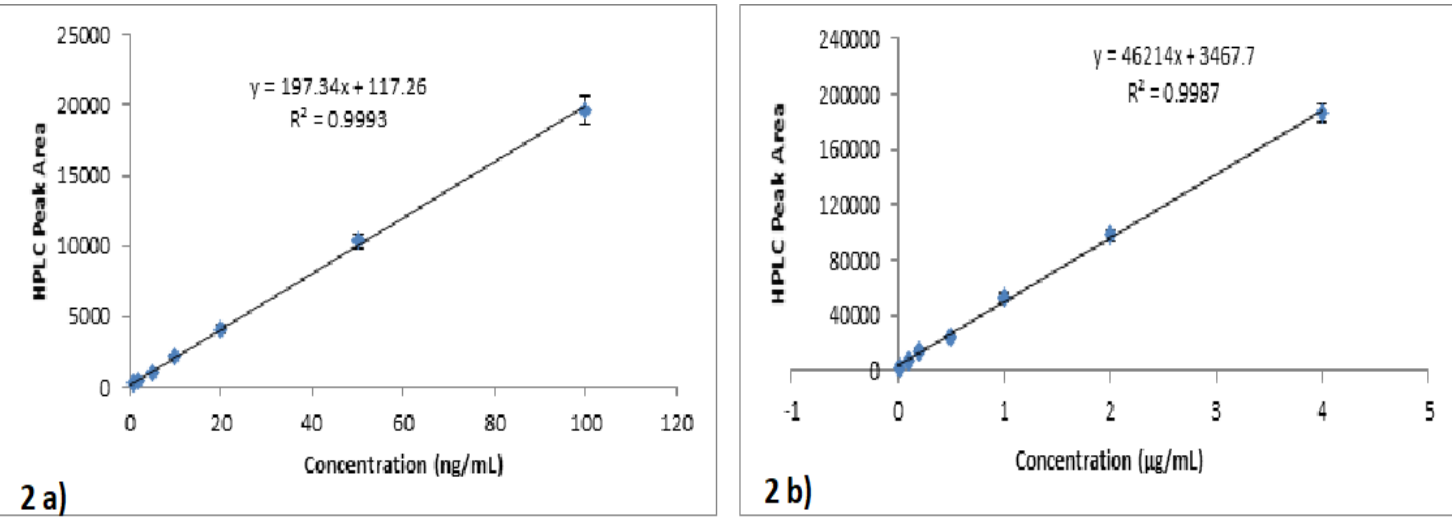

Fig. 2: a) Calibration curve of clopidogrel in rat plasma using HPLC b) Calibration curve of dipyridamole in rat plasma using HPLC. The results were expressed as mean $\pm S D$ for $n=3$

Table 1: Linearity test results of estimation of clopidogrel in rat plasma using HPLC

\begin{tabular}{|c|c|c|}
\hline S. No. & Parameter & Result observed \\
\hline 1 & Concentration range $(\mathrm{ng} / \mathrm{ml})$ & $1-100 \mathrm{ng} / \mathrm{ml}$ \\
\hline \multirow[t]{2}{*}{2} & Retention time (min.) Diclofenac sodium & 2.045 \\
\hline & Clopidogrel & 5.121 \\
\hline 3 & Regression equation & $y=197.34 x+117.26$ \\
\hline 4 & Slope & 197.34 \\
\hline 5 & Intercept & 117.26 \\
\hline 6 & Correlation coefficient & 0.9993 \\
\hline
\end{tabular}

Table 2: Linearity test results of estimation of dipyridamole in rat plasma using HPLC

\begin{tabular}{llll}
\hline S. No. & Parameter & Result observed \\
\hline 1 & Concentration range $(\mu \mathrm{g} / \mathrm{ml})$ & $0.02-4 \mu \mathrm{g} / \mathrm{ml}$ \\
2 & Retention time (min.) & Diazepam & 1.408 \\
& & Dipyridamole & 2.163 \\
3 & Regression equation & & $\mathrm{y}=46214 \mathrm{x}+3467.7$ \\
4 & Slope & 46214 \\
5 & Intercept & 3467.7 \\
6 & Correlation coefficient & & 0.9987 \\
\hline
\end{tabular}

Table 3: Accuracy and precision results of clopidogrel and dipyridamole

\begin{tabular}{llll}
\hline Test & & Clopidogrel & Dipyridamole \\
\hline Accuracy & \% Mean recovery & 100.02 & 99.79 \\
& \% RSD & 0.467 & 0.733 \\
Precision & \%RDD & 0.459 & 0.716 \\
\hline
\end{tabular}

*RSD-Relative standard deviation 

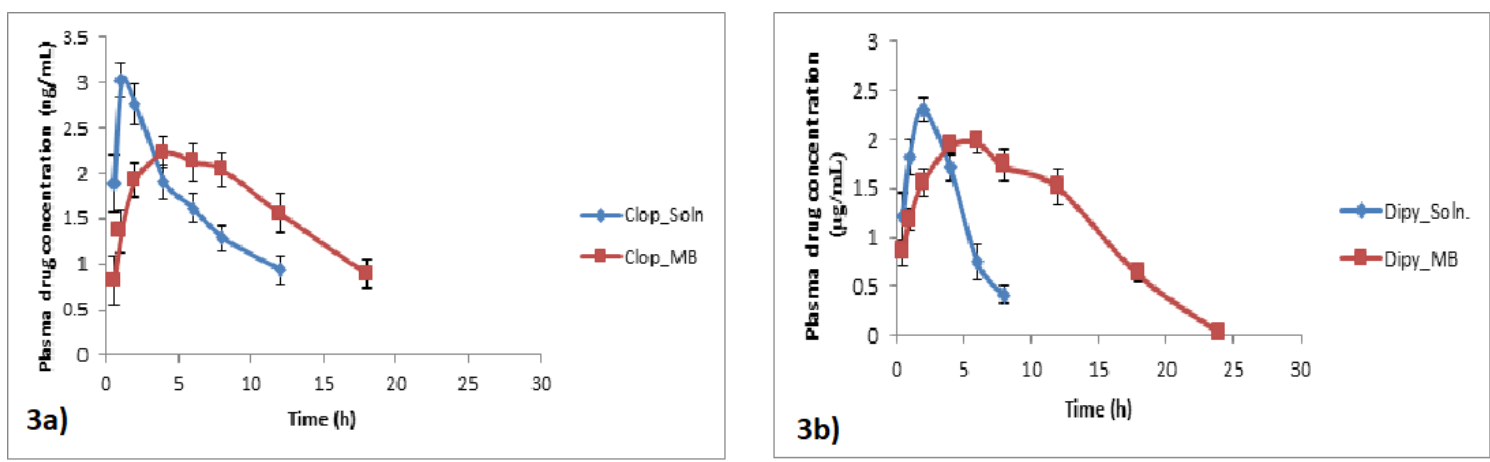

Fig. 3: Time versus plasma drug concentration profiles of a) Clopidogrel solution and clopidogrel floating microballoons. b) Dipyridamole solution and dipyridamole floating microballoons. The results were expressed as mean $\pm \mathrm{SD}$ for $\mathrm{n}=3$

Table 4: Results of pharmacokinetic properties after non-compartmental analysis (using PK Solver) for the data obtained from in vivo pharmacokinetic studies of clopidogrel floating microballoons

\begin{tabular}{lllll}
\hline S. No. & Pharmacokinetic parameter & Observed result $^{*}$ & p-Value from ANOVA \\
\cline { 3 - 4 } & & Clop_Soln & Clop_MB & 0.0283 \\
\hline 1 & $\mathrm{C}_{\max }(\mathrm{ng} / \mathrm{ml})$ & $3.02 \pm 0.37$ & $2.23 \pm 0.17$ & - \\
2 & $\mathrm{~T}_{\max }(\mathrm{h})$ & 1.0 & 4.0 & 0.0042 \\
3 & AUC $(\mathrm{ng} . \mathrm{h} / \mathrm{ml})$ & $30.36 \pm 2.14$ & $40.22 \pm 1.97$ & - \\
4 & AUMC $\left(\mathrm{ng} . \mathrm{h}^{2} / \mathrm{ml}\right)$ & $334.55 \pm 3.96$ & $558.87 \pm 4.08$ & 0.1467 \\
5 & $\mathrm{MRT}(\mathrm{h})$ & $11.02 \pm 1.85$ & $13.9 \pm 2.07$ & -- \\
6 & $\mathrm{k}_{\mathrm{e}}\left(\mathrm{h}^{-1}\right)$ & $0.091 \pm 0.007$ & $0.084 \pm 0.006$ & -- \\
7 & $\mathrm{t}_{1 / 2}(\mathrm{~h})$ & $7.63 \pm 0.59$ & $8.27 \pm 0.61$ & \\
\hline
\end{tabular}

${ }^{*}$ Results were shown as mean \pm SD for $\mathrm{n}=3$. $\mathrm{C}_{\max }$ : Peak plasma concentration; $\mathrm{T}_{\max }$ : Time for Peak plasma concentration; AUC: Area under the curve; AUMC: Area under the first momentum curve; MRT: Mean residence time; $\mathrm{k}_{\mathrm{e}}$ : Elimination rate constant; $\mathrm{t}_{1 / 2}$ : Elimination half-life; ANOVA: Analysis of variance

Table 5: Results of pharmacokinetic properties after non-compartmental analysis (using PK Solver) of data obtained from in vivo pharmacokinetic studies on Dipyridamole floating microballoons

\begin{tabular}{lllll}
\hline S. No. & $\begin{array}{l}\text { Pharmacokinetic } \\
\text { parameter }\end{array}$ & Observed result $^{*}$ & & p-Value from ANOVA \\
\cline { 2 - 5 } & $\mathrm{D}_{\max }(\mathrm{ng} / \mathrm{ml})$ & $2.3 \pm 0.13$ & $1.97 \pm 0.11$ & 0.0284 \\
\hline 1 & $\mathrm{~T}_{\max }(\mathrm{h})$ & 2.0 & 6.0 & - \\
2 & $\mathrm{AUC}(\mathrm{ng} . \mathrm{h} / \mathrm{ml})$ & $11.89 \pm 1.52$ & $28.09 \pm 2.11$ & 0.0004 \\
3 & $\mathrm{AUMC}\left(\mathrm{ng} \cdot \mathrm{h}^{2} / \mathrm{ml}\right)$ & $46.93 \pm 2.07$ & $248.58 \pm 3.82$ & - \\
4 & $\mathrm{MRT}(\mathrm{h})$ & $3.94 \pm 1.36$ & $8.85 \pm 1.81$ & 0.0198 \\
5 & $\mathrm{k}_{\mathrm{e}}\left(\mathrm{h}^{-1}\right)$ & $0.35 \pm 0.031$ & $0.33 \pm 0.023$ & -- \\
6 & $\mathrm{t}_{1 / 2}(\mathrm{~h})$ & $1.94 \pm 0.17$ & $2.12 \pm 0.15$ & -- \\
7 & & &
\end{tabular}

*Results were shown as mean \pm SD for $n=3$. $C_{\text {max }}$ : Peak plasma concentration; $T_{\text {max }}$ Time for Peak plasma concentration; AUC: Area under the curve; AUMC: Area under the first momentum curve; MRT: Mean residence time; $\mathrm{k}_{\mathrm{e}}$ : Elimination rate constant; $\mathrm{t}_{1 / 2}$ : Elimination half-life; ANOVA: Analysis of variance

It was inferred from the chromatograms of the drug in rat plasma that a peak at $2.045 \mathrm{~min}$ of diclofenac and another peak at $5.121 \mathrm{~min}$ is of clopidogrel were obtained as shown in fig. 1a. A peak at 1.408 min of diazepam and another peak at $2.163 \mathrm{~min}$ is of dipyridamole were obtained as shown in fig. $1 \mathrm{~b}$.

The quantification of clopidogrel and dipyridamole in rat plasma during in vivo studies was carried by developing calibration curve using HPLC; considering diclofenac sodium and diazepam as the internal standards respectively, the drug and internal standard from plasma was effectively extracted with acetonitrile by liquid-liquid extraction. At a concentration range of 1-100 $\mathrm{ng} / \mathrm{ml}$ for clopidogrel (table 1) and $0.02-4 \mu \mathrm{g} / \mathrm{ml}$ for dipyridamole (table 2), linearity was observed with correlation coefficient of 0.9993 and 0.9987 respectively as shown in fig. 2 . It can be inferred from this result that the linearity was established [14] and could be successfully used for the estimation of drug in the concentration range of $1-100 \mathrm{ng} / \mathrm{ml}$ for clopidogrel and 0.02-4 $\mu \mathrm{g} / \mathrm{ml}$ dipyridamole biological samples.

The accuracy of the method was found to be satisfactory as the mean recovery and \%RSD were found to be $100.019 \%$ and $0.4675 \%$ for clopidogrel and $99.791 \%$ and $0.733 \%$ for dipyridamole respectively as shown in table 3 and the recovery method is found to be significant as the mean recovery was within the range of $98 \%$ to $102 \%$ and the $\%$ RSD was not more than $+2.0 \%$ in both clopidogrel and dipyridamole. These results indicated that the developed method was accurate, as evidenced by Sahai M et al. [15] and Patil PM et al. [16].

The results of the precision determination studies show that upon repetition of the prepared sample injection for ten times, the \%RSD calculated from the mean and the standard deviation was found to be $0.459 \%$ for clopidogrel and $0.716 \%$ for dipyridamole as shown in table 3 . The low values of \%RSD indicate that the precision of the method is high as the \%RSD values were not more than+2.0\% [17] and were correlated with those reported by Sahai M et al. [15].

The LOD and LOQ for clopidogrel were found to be $0.2 \mathrm{ng} / \mathrm{ml}$ and 0.6 $\mathrm{ng} / \mathrm{ml}$ respectively; whereas these values for dipyridamole were found to be $5.3 \mathrm{ng} / \mathrm{ml}$ and $16.1 \mathrm{ng} / \mathrm{ml}$, respectively. These values suggested that this method could quantify any amount of the drugs above their LOQ values $(0.6 \mathrm{ng} / \mathrm{ml}$ for clopidogrel and $16.1 \mathrm{ng} / \mathrm{ml}$ for dipyridamole $)$ in biological samples taken from the pharmacokinetic studies. 
For the pure drug solutions, the optimized formulation of clopidogrel bisulfate and the optimized formulation of dipyridamole, the in vivo pharmacokinetic studies were performed in Wistar male rats for which the results were shown in fig. 3 . The pharmacokinetic parameters of clopidogrel were shown in table 4 and dipyridamole in table 5, which were obtained using PK Solver software to analyze the plasma concentration time data by non-compartmental model.

In both the clopidogrel and dipyridamole microballoons, the increased $\mathrm{T}_{\max }(p<0.05)$ and decreased $\mathrm{C}_{\max }(p<0.05)$ than the pure drug solution inferred to the slow and extended absorption of drug due to its sustained release from the formulated microballoons. The AUC was found to be increased $(p<0.05)$ by $33.3 \%$ and $154.5 \%$ for clopidogrel and dipyridamole microballoons respectively when compared to their pure drug which might be attributed to the sustained release of drug from the microballoons in the stomach. These results were evidenced by the results published by $\mathrm{P} \mathrm{K}$ et al. [18]. The pharmacokinetic studies also elucidated the increase in the mean residence time of the drug as shown in the table 4 and 5 , when formulated as microballoons when compared to the pure drug. This could be attributed to the prolonged residence of the microballoons in the stomach. The study results inferred that the effective sustain release from the developed microballoons and their absorption with increased bioavailability was achieved because of floating in the stomach $[19,20]$

\section{CONCLUSION}

In the current study, the optimized formulations of clopidogrel microballoons and dipyridamole floating microballoons were subjected to in vivo pharmacokinetic studies and the results elucidated the enhanced bioavailability of the drugs upon formulated as floating microballoons when compared to their pure drug solutions. The pharmacokinetic studies also confirm the increase in the mean residence time of the drugs when formulated as microballoons. The results obtained in this research work suggested that the floating microballoons act as an alternative to conventional oral dosage form also other sustained release dosage forms in enhancing bioavailability of the drug thereby improving the therapeutic efficacy of the drug.

\section{FUNDING}

Nil

\section{AUTHORS CONTRIBUTIONS}

All authors have contributed equally.

\section{CONFLICT OF INTERESTS}

\section{Declared none}

\section{REFERENCES}

1. Bazzo GC, Pezzini BR, Stulzer HK. Eutectic mixtures as an approach to enhance solubility, dissolution rate and oral bioavailability of poorly water-soluble drugs. Int J Pharm. 2020;588:119741. doi: 10.1016/j.ijpharm.2020.119741.

2. Beg S, Swain S, Rizwan Md, Irfanuddin Md, Malini DS. Bioavailability enhancement strategies: basics, formulation approaches and regulatory considerations. Curr Drug Delivery. 2011;8(6):691-702. doi: 10.2174/156720111797635504, PMID 21864253.

3. Jain HK, Deere DD. Bioanalytical method development and validation for estimation of clopidogrel bisulfate in human plasma by RP-HPLC. Int J Appl Pharm. 2016;8:18-21.

4. Vanshiv SD, Joshi HP, Aware AB. Formulation and development of gastroretentive dipyridamole microspheres: proof of concept by in vitro in vivo assessment. Pharm Sci.
2018;80(1):181-91. doi: 10.4172/pharmaceuticalsciences.1000343.

5. Joseph NJ, Lakshmi S, Jayakrishnan A. A floating-type oral dosage form for piroxicam based on hollow polycarbonate microspheres: in vitro and in vivo evaluation in rabbits. J Controlled Release. 2002;79(1-3):71-9. doi: 10.1016/s01683659(01)00507-7, PMID 11853919.

6. Javed MK, Iqbal Z, Khan A, Khan A, Shah Y, Ahmad L. Development and validation of HPLC-UV method for the determination of clopidogrel in pharmaceutical dosage form and human plasma. J Liq Chromatogr Relat Technol. 2011;34(18):2118-29. doi: 10.1080/10826076.2011.585482.

7. Qin T, Qin F, Li N, Lu S, Liu W, Li F. Quantitative determination of dipyridamole in human plasma by high-performance liquid chromatography-tandem mass spectrometry and its application to a pharmacokinetic study. Biomed Chromatogr. 2010;24(3):268-73. doi: 10.1002/bmc.1283, PMID 19630071.

8. Nagavi JB, Gurupadayya B. Simultaneous estimation of clopidogrel and atorvastatin in human plasma using bioanalytical RP-Ultra fast liquid chromatographic method. Int J Curr Pharm Res. 2015;7:30-5.

9. Housheh S, Ali D, Trefi S, Mohammad H, Chehna MF. Optimization of RP-HPLC assay for pharmaceutical analysis of clopidogrel. Int J Pharm Sci Nanotechnol. 2014;7(1):2371-6. doi: 10.37285/ijpsn.2014.7.1.9.

10. International Conference on Harmonization (ICH) of Technical Requirements for the Registration of Pharmaceuticals for Human Use, Validation of analytical procedures: Text and Methodology. ICH-Q2B. Geneva; 1996.

11. Awasthi R, Kulkarni GT, Pawar VK, Garg G. Optimization studies on gastroretentive floating system using response surface methodology. AAPS PharmSciTech. 2012;13(1):85-93. doi: 10.1208/s12249-011-9730-y, PMID 22135108.

12. Yang Z, Song B, Li Q, Fan H, Ouyang F. Preparation of microspheres with microballoons inside for floating drugdelivery systems. J Appl Polym Sci. 2004;94(1):197-202. doi: 10.1002/app.20856.

13. Nair $A B$, Jacob $S$. A simple practice guide for dose conversion between animals and human. J Basic Clin Pharm. 2016;7(2):2731. doi: 10.4103/0976-0105.177703, PMID 27057123.

14. Kamala G, Vadrevu S, Valli KN. Development and validation of RP-HPLC method for simultaneous estimation of lamivudine and zidovudine in bulk. Int J Curr Pharm Sci. 2016;8:28-33.

15. Sahai M, Devanna N. Validated stability-indicating HPLC approach for quantifying tricholine citrate and cyproheptadine simultaneously in syrup forms. Int J Appl Pharm. 2021;13:20713.

16. Patil PM, Bobade AS. Development and validation of stability indicating RP-HPLC for determination of atorvastatin calcium and ezetimibe in bulk and pharmaceutical dosage forms. Int J Pharm Pharm Sci. 2016;8:38-2.

17. Grace AC, Prabha T, Jagadeeswaran M, Srinivasan K, Sivakumar T. Analytical method development for simultaneous determination of ubidecarenone and vitamin $\mathrm{E}$ acetate in capsule dosage form by HPLC. Int J Pharm Pharm Sci. 2019;11:79-84. doi: 10.22159/ijpps.2019v11i1.30054.

18. PK, Dvrn B. Development and in vivo evaluation of mucoadhesive microspheres using pirenzepine. Asian J Pharm Clin Res. 2018;11:296-302.

19. PP, KA, KM. Gastro-floating tablets of repaglinide: preparation and in vivo evaluation. Asian J Pharm Clin Res. 2018;11:291-5.

20. Husseiny RA, Abu Lila AS, Abdallah MH, Hamed EE, El-ghamry HA. Design, in vitro/in vivo evaluation of meclizine HCl-loaded floating microspheres targeting pregnancy-related nausea and vomiting. J Drug Delivery Sci Technol. 2018;47:395-403. doi: 10.1016/j.jddst.2018.08.012. 